\title{
Study of Corrosion Properties, Adsorption Mechanism and Thermodynamics Characteristics of Expired Artemether-Lumefantrine Inhibition Drug on Mild Steel in NaCl Solution
}

\author{
O.A. Odunlami ${ }^{{ }^{*}}$, S.K.U Tijani ${ }^{a}$, O.S.I. Fayomi ${ }^{\text {b,c, }}$, \\ ${ }^{a}$ Chemical Engineering Department, Covenant University, Ota, Ogun State, Nigeria. \\ ${ }^{b}$ Mechanical Engineering Department, Covenant University, Ota, Ogun State, Nigeria. \\ ${ }^{c}$ Chemical, Metallurgical and Materials Engineering Department, Tshwane University of Technology, Pretoria, South Africa.
}

\begin{abstract}
In this study, electrochemical and structural pitting effect of Artemether/Lumefantrine inhibitive drug was examined as a corrosion inhibitor for mild steel in $0.625 \mathrm{M}$ sodium chloride $(\mathrm{NaCl})$ medium using both weight loss and potentiodynamic polarisation method. The effect expired drug was assessed with thermodynamic parameters from temperature variation and adsorption mechanism. Surface morphological assessment was also carried out using scanning electron microscope (SEM) and energy dispersive x-ray spectroscopy (EDS) analyses. The results obtained shows that artemether/lumefantrine inhibits the corrosion of mild steel in $0.625 \mathrm{M}$ salt solution fairly well with an inhibition efficiency of up to $75 \%$ at $298 \mathrm{~K}$ at $20 \mathrm{ml}$ of the inhibitor. The inhibition efficiency reduced with increase in temperature but increased with increase in inhibitor concentration which suggests that the inhibition efficiency is inversely proportional to temperature but directly proportional to concentration. It operates with the mixed inhibition method since both the cathodic and anodic reactions were affected by the addition of the inhibitor. Langmuir adsorption isotherm best matches the behaviour of the inhibitor in the study with a minimum correlation coefficient of 0.975 .
\end{abstract}

Keywords: Adsorption, thermodynamics, corrosion, mild steel, drugs,

\section{INTRODUCTION}

Mild steel is usually described as the most commonly used structural material in engineering fields [1]. It is used for various applications because of its low cost, wide range of available forms and sizes as well as its malleability, ductility and ease of welding. It also has good tensile strength [2]. However, it is very likely to corrode in most environments and thus various treatment methods have been considered [36]. In the marine sector, mild steel is considered to be the best metal for use in construction due to its low cost, mechanical strength and simple process of fabrication [7]. The main disadvantage is that it tends to corrode rapidly in marine media and would lose strength quickly when it is not sufficiently protected which usually leads to failure and collapse of its structures [8].

Recently, green chemistry has aroused a lot of interest in many fields involving the design of chemicals, chemical technologies, and various other products in order to reduce the amount of toxins or harmful wastes [9-11]. There was already a growing concern about waste generation and the elimination of hazards and toxins [12]. The increase in environmental awareness was incited by the Pollution and Prevention Act in 1990 by the USA [13-15].

Corrosion inhibitors are widely used when the corrosion of metals needs to be stalled [16]. Many synthetic compounds proved to be good corrosion inhibitors but there have been concerns about them globally because of their toxicity and effect on the environment [17-19] Due to this, green inhibitors have become one of the major focuses in the corrosion field as they are safer, biodegradable and renewable [20]. Estimates show that the U.S. alone will need about $4.1 \%$ more inhibitors per year to a cost of $\$ 2.5$ billion from 2017 . The market demand for corrosion inhibitors in 2012 was distributed as such: $26.6 \%$ from petroleum refineries, $16.9 \%$ from utilities, $16.7 \%$ from the oil and gas sector, $15.3 \%$ from the chemical industry, $9.5 \%$ from the metal industry, $7.1 \%$ from the pulp and paper industry and $8.0 \%$ from other fields [21].

Most organic and heterocyclic compounds which contain oxygen, nitrogen and sulphur are known to be effective inhibitors [22]. However, majority of them are expensive, or harmful to people and the environment. These properties limit the applicability of these compounds as inhibitors. As such, the need to develop cheaper and safer inhibitors cannot be overemphasized [23]. In recent years, drugs have been used as corrosion inhibitors since they are not harmful to the environment. They are not toxic, cheap, and have almost no effect on environment. Thus, they are considered as adequate replacements for the toxic corrosion inhibitors [24].

Many researchers suggest that drugs can perform just as well as green corrosion inhibitors especially since they are usually synthesized from natural products (Pathak \& Mishra, 2013). Drugs are often chosen as corrosion inhibitors due to the fact that they contain oxygen, nitrogen and sulphur in their organic molecules, they are not harmful to the environment and they are easy to produce and purify [25]. Artemether is a derivative 
of artemisinin wherein the lactone group has been converted to a lactol methyl ether corresponding to it. It is usually combined with lumefantrine for the treatment of multi-drug resistant strains of falciparum malaria [26]. It is a sesquiterpenoid, a cyclic acetal, an organic peroxide, an artemisinin derivative and a semisynthetic derivative. Artemether is a drug with chemical formula $\mathrm{C}_{16} \mathrm{H}_{26} \mathrm{O}_{5}$ commonly used in combination with Lumefantrine (benflumetol) to treat malaria which cannot be treated using chloroquine. It is on the World Health Organisation's list of essential medicines and is considered one of the safest and most effective medicines [25-28] Lumefantrine is also referred to as co-artemether. It is a drug with chemical formula $\mathrm{C}_{30} \mathrm{H}_{32} \mathrm{Cl}_{3} \mathrm{NO}$. It is only ever used for antimalarial treatments in combination with artemether. It is used in smaller amounts than artemether however [28, 29]. The current information on the inhibition properties of mild steel with Artemether/Lumefantrine expire inhibitive drug is scanty. Thus, this paper aim to examine the adsorption mechanism and thermodynamics characteristics of expired of Artemether-Lumefantrine inhibition drug on mild steel in $\mathrm{NaCl}$ solution.

\section{EXPERIMENTAL METHODS}

\subsection{Materials and Sample Preparation}

Twenty-five coupon samples of mild steel was cut into rectangles coupon of $10 \mathrm{~mm} \times 10 \mathrm{~mm} \times 2 \mathrm{~mm}$ with an average area of about $1 \mathrm{~cm}^{2}$ used in the course of this study. The steel plate purchased from a metal processing vendor in Ota, Nigeria, was analyzed accordingly to obtain the elemental composition. Two grades of emery paper were used to remove impurities from the surface of the metals as well as to ensure adequate smoothness of the surface before the tests. Sodium chloride was obtained and supplied to Surface Engineering Research Laboratory, Covenant University from SigmaAldrich, USA. Artemether/Lumefantrine expired inhibitive drug were obtained in powder nature from Pharmaceutical Company in Ota, Ogun state.

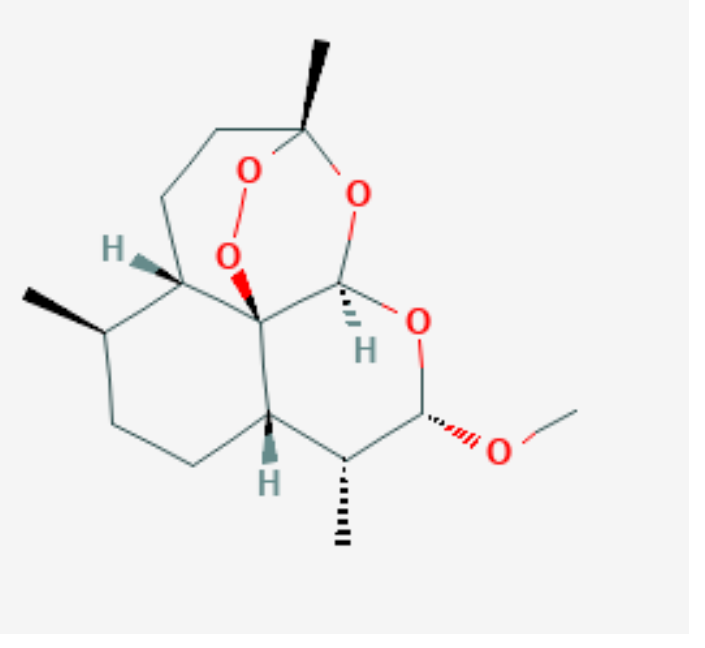

Figure 1: Artemether chemical structure

\subsection{Test solution preparation and analysis}

The corrosive medium used in the experiment was 0.625 molar sodium chloride solutions. The solution was prepared by weighing out 32.5 grams of anhydrous sodium chloride granules of about $95 \%$ purity. The granules were placed in a measuring cylinder while distilled water was added until the mixture was 1 litre. The mixture was then stirred to ensure complete dissolution of the salt in the water. Powder containing 90 milligrams of Artemether and 15 milligrams of Lumefantrine was poured into a measuring cylinder and then distilled water was added to make up a 120-millilitre mixture. Tests were carried out without the inhibitor at $5 \mathrm{ml}, 10 \mathrm{ml}$, $15 \mathrm{ml}$ and $20 \mathrm{ml}$ of inhibitor at various temperatures. The principle of testing followed study done by $[25,27]$

\subsection{Electrochemical tests}

After all the required materials had been prepared, the electrochemical tests were carried out. Metal samples were placed in a beaker containing $50 \mathrm{ml}$ salt solution acting as the corrosive medium. The corrosion propagation was done using AUTO LAB PGSTAT 101 potentiostat galvanostat device with Nova 2.1 software. The spontaneous chemical interaction of the inhibitive properties of the Artemether Lumefantrine drug on mild steel was examined using the potentiodynamic polarization technique. The design procedure in Table 1 was follow and all materials were subjected to (salty) environments at an ambient temperature of $35^{\circ} \mathrm{C}, 40{ }^{\circ} \mathrm{C}, 45$ ${ }^{\circ} \mathrm{C}$ and $50{ }^{\circ} \mathrm{C}$. A three conventional electrode cell consisting of the reference electrode, working electrode, and counter electrode with a beaker filled with $100 \mathrm{ml}$ of electrolyte was used. With the mild steel as the working electrode, silver chloride as the reference electrode, and graphite rod as the counter electrode, the configuration was connected to AUTO LAB PGSTAT 101 Metrohm. The Tafel plot was attained within $-1.5 \mathrm{~V}$ and $+1.5 \mathrm{~V}$ and a scan rate of $0.0012 \mathrm{~V} / \mathrm{s}$. The preparation was carried out just before each of the corrosion tests. The samples were divided based on the testing conditions shown in the table 1

Table 1: Experimental design of mild steel corrosion tests in $0.625 \mathrm{M}$ salt solution with Artemether/Lumefantrine inhibitor

\begin{tabular}{|c|c|c|c|}
\hline $\begin{array}{c}\text { Sample } \\
\text { number }\end{array}$ & $\begin{array}{c}\text { Inhibitor } \\
\text { Concentration } \\
(\mathbf{m l})\end{array}$ & $\begin{array}{c}\text { Temperature } \\
(\mathbf{k})\end{array}$ & $\begin{array}{c}\text { Medium } \\
\text { Concentration } \\
(\mathbf{m l})\end{array}$ \\
\hline 1 & 0 & 298 & 50 \\
\hline 2 & 5 & 298 & 50 \\
\hline 3 & 10 & 298 & 50 \\
\hline 4 & 15 & 298 & 50 \\
\hline 5 & 20 & 298 & 50 \\
\hline 6 & 0 & 308 & 50 \\
\hline 7 & 5 & 308 & 50 \\
\hline 8 & 10 & 308 & 50 \\
\hline 9 & 15 & 308 & 50 \\
\hline 10 & 20 & 308 & 50 \\
\hline
\end{tabular}




\begin{tabular}{|c|c|c|c|}
\hline $\begin{array}{c}\text { Sample } \\
\text { number }\end{array}$ & $\begin{array}{c}\text { Inhibitor } \\
\text { Concentration } \\
(\mathbf{m l})\end{array}$ & $\begin{array}{c}\text { Temperature } \\
(\mathbf{k})\end{array}$ & $\begin{array}{c}\text { Medium } \\
\text { Concentration } \\
(\mathbf{m l})\end{array}$ \\
\hline 11 & 0 & 313 & 50 \\
\hline 12 & 5 & 313 & 50 \\
\hline 13 & 10 & 313 & 50 \\
\hline 14 & 15 & 313 & 50 \\
\hline 15 & 20 & 313 & 50 \\
\hline 16 & 0 & 318 & 50 \\
\hline 17 & 5 & 318 & 50 \\
\hline 18 & 10 & 318 & 50 \\
\hline 19 & 15 & 318 & 50 \\
\hline 20 & 20 & 318 & 50 \\
\hline 21 & 0 & 323 & 50 \\
\hline 22 & 5 & 323 & 50 \\
\hline 23 & 10 & 323 & 50 \\
\hline 24 & 15 & 323 & 50 \\
\hline 25 & 20 & 323 & 50 \\
\hline
\end{tabular}

Corrosion rate is the amount of the metal lost due to deterioration per unit time at a specified surface [8]. Faraday's law is often used to obtain the corrosion rate of any species of material in weight lost per ampere of current flow per unit time. The corrosion rate was obtained using equation 1

$$
C_{r}=\frac{3.27 * i_{c o r r} * W_{e}}{D}
$$

Where $C_{r}$ is the corrosion rate in $\mathrm{mm} /$ year, $i_{\text {corr }}$ is the current density, $\mathrm{D}$ is the density of the metal and $\mathrm{W}_{\mathrm{e}}$ is the weight of the metal.

The inhibition efficiency $(N)$ of the Artemether/Lumefantrine solution was found by relating the calculated by using the relationship represented below in equation 2:

$$
N(\%)=\frac{W o-W i}{W o} \times 100 \%
$$

Where Wo is the initial mass of metal sample and Wi is the final mass of metal sample. Inhibition efficiency was found for $5 \mathrm{ml}, 10 \mathrm{ml}, 15 \mathrm{ml}$ and $20 \mathrm{ml}$ of the inhibitor at room temperature, $35^{\circ} \mathrm{C}, 40{ }^{\circ} \mathrm{C}, 45^{\circ} \mathrm{C}$ and $50{ }^{\circ} \mathrm{C}$.

\subsection{Adsorption Isotherms and thermodynamics mechanism}

The adsorption behaviour was tested against the Langmuir, Temkin, Freundlich, El-Awady and Flory Huggins adsorption isotherms. The correlation coefficients of the isotherms were found and then compared to find the best fit. Langmuir adsorption model prediction was initially created as a means of characterising gas adsorption onto solid surfaces. Equation 3 gives the Langmuir adsorption isotherm:

$$
\frac{C}{\theta}=\frac{1}{K_{a d s}}+C
$$

With freundlich adsorption isotherm the model is usually applied to adsorption on heterogenous surfaces and subsequently to define the exponential distribution of active sites, their energies and the surface heterogeneity [3]. The Freundlich adsorption isotherm is represented by equation 4 :

$$
\log \theta=\log K_{F}+\log C
$$

For Temkin adsorption isotherm the effects of indirect interactions between the adsorbate on the adsorption process especially when heat of adsorption of all molecules in the layer are inversely proportional to the surface coverage. It is only valid for an intermediate range of concentrations. The Temkin isotherm is shown by equation 5

$$
\theta=\frac{R t}{b} \log K+\frac{R T}{b} \log C
$$

The Flory-Huggins adsorption isotherm is obtained using the relationship in equation 6 , considering the surface coverage feasible and adsorption spontaneous process is.

$$
\log \frac{\theta}{C}=\log K_{F H}+n \log (1-\theta)
$$

Where $\mathrm{C}$ is the inhibitor concentration, $\theta$ is the surface coverage $\mathrm{K}_{\mathrm{ads}}$ is the adsorption coefficient $\mathrm{b}$ is the Temkin constant and $\mathrm{K}_{\mathrm{FH}}$ is the Flory-Huggins coefficient.

The thermodynamic properties were ascertained by comparing the inhibitor's performance at different temperatures. The activation energy was obtained using the Arrhenius equation which is shown in equation 7.

$$
\log C_{r}=\frac{-E_{a}}{2.303 R T}+\log \lambda
$$

\subsection{Surface Characterisation}

The structural adsorption behaviour of the inhibitor was determined using a Scanning Electron Microscopy (SEM) and Energy Dispersive X-ray Spectroscopy (EDS) analysis for elemental quantification and effect of corrosion product on the corroded metal.

\section{RESULTS AND DISCUSSION}

Figs 2 to 4 give the corrosion parameters obtained for the metal samples tested with varying concentrations of inhibitor at $298 \mathrm{~K}, 308 \mathrm{~K}, 313 \mathrm{~K}, 318 \mathrm{~K}$ and $323 \mathrm{~K}$ respectively. The mass loss, corrosion rate, surface coverage and inhibition efficiency were all recorded. Figure 2 shows the relationship between the concentration of Artemether/Lumefantrine inhibitor used and the mass of mild steel lost in $0.625 \mathrm{M}$ salt solution at temperatures between $298 \mathrm{~K}$ and $323 \mathrm{~K}$. The figure shows a reduction in the quantity of mass lost with increase in inhibitor concentration. This implies that the Artemether/Lumefantrine inhibitor suppresses the rate of corrosion in the salt solution medium. It occurs due to the coverage of the metals' surfaces by a layer of the inhibitor which limits the corrosion reaction and thus prevents the loss of material which accounts for the lower mass loss. 


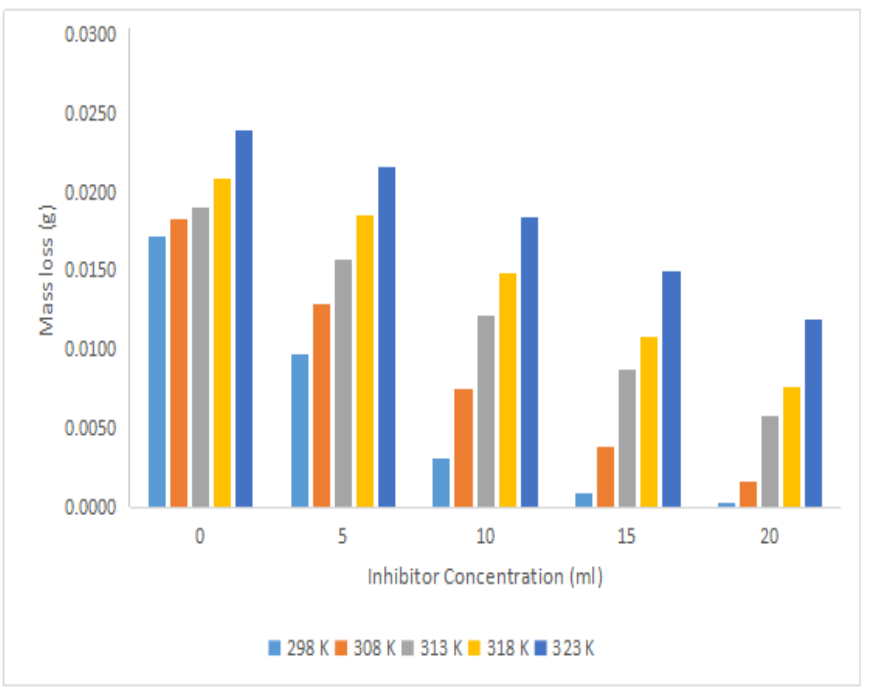

Figure 2: Mass loss against inhibitor concentration

Comparing the corrosion rates of the metal with the temperatures as shown in Fig 3, it can be noticed that an increase in temperature leads to an increase in corrosion rate. This implies that temperature is directly proportional to the rate of corrosion and thus inversely proportional to the inhibition efficiency. The highest corrosion rate was found in the absence of inhibitor at $323 \mathrm{~K}$ at about $26 \mathrm{~mm} /$ year and the lowest corrosion rate was at $298 \mathrm{~K}$ with $20 \mathrm{ml}$ artemether/lumefantrine. Figure 4 shows a decrease in inhibition efficiency with increase in temperature. Thus, an inverse relationship is observed between the Artemether/Lumefantrine inhibitor efficiency and the temperature of the medium. This behaviour is most likely due to desorption of inhibitor from the surface of the metals at higher temperatures thus leaving the metals' surfaces exposed to the effect of the corrosive medium. As such, physical adsorption can be assumed.

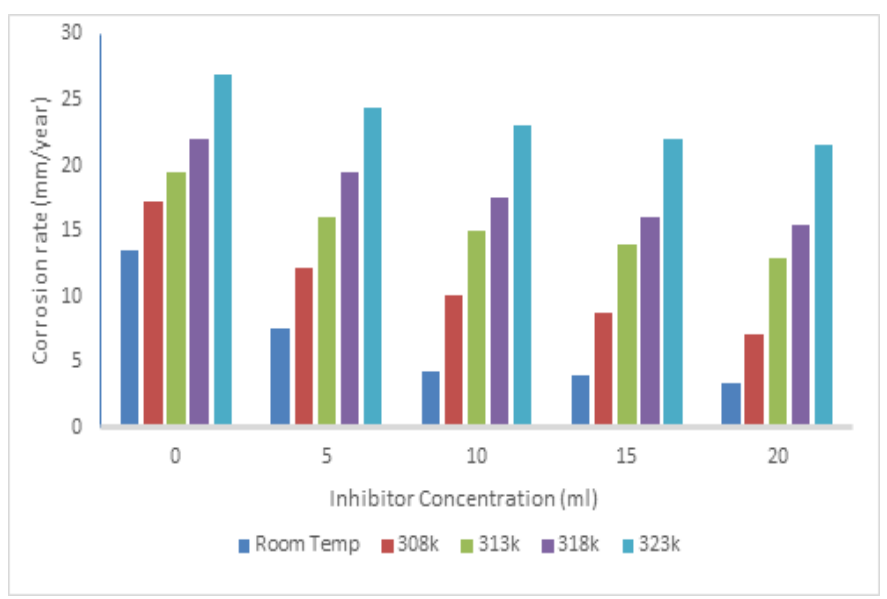

Figure 3: Corrosion Rate against Inhibitor Concentration for Mild Steel in $0.625 \mathrm{M} \mathrm{NaCl}$ with Artemether / Lumefantrine Inhibitor for various temperatures

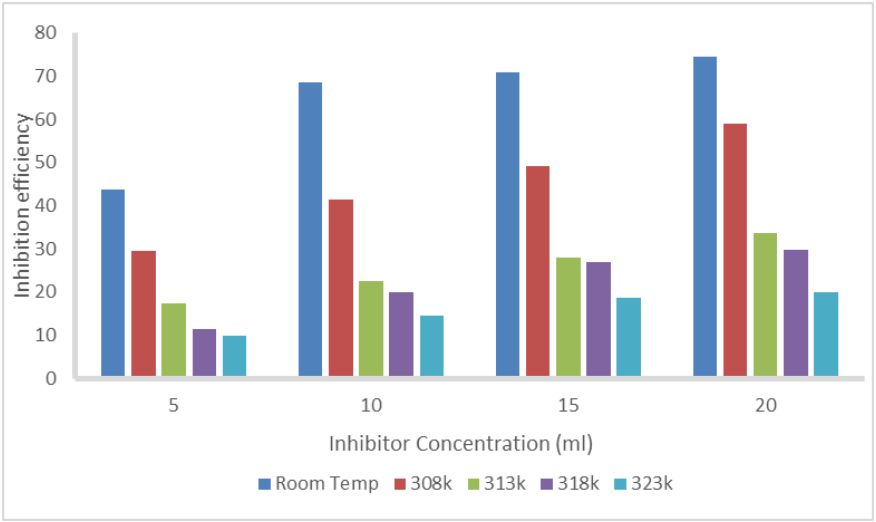

Figure 4: Inhibitor efficiencies (\%) against Inhibitor Concentration for Artemether / Lumefantrine inhibitor in $0.625 \mathrm{M} \mathrm{NaCl}$ medium at $298 \mathrm{~K}-323 \mathrm{~K}$

Figures 5a-e give the polarisation curves for the mild steel samples in $0.625 \mathrm{M}$ salt solution at various concentrations of the Artemether/Lumefantrine inhibitor with each graph representing the behaviour at a temperature of $298 \mathrm{~K}, 308 \mathrm{~K}$, $313 \mathrm{~K}, 318 \mathrm{~K}$ and $323 \mathrm{~K}$. The polarisation was carried out for ten minutes for each sample with a scan rate of 0.01 volts/second and a step of $2.5 \mathrm{mV}$. The anodic dissolution reaction is represented in the top half above the intersection line of each graph and the cathodic hydrogen evolution reaction. The figures show that increase in inhibitor concentration suppresses both the anodic and cathodic reactions since both the anodic and cathodic curves showed a decrease in current density in the presence of the inhibitor. This submits that the inhibitor acts as a mixed type [1].

Table 2 gives the electrochemical data of the metal samples with varying concentrations of the artemether/lumefantrine inhibitor at temperatures ranging from $298 \mathrm{~K}$ to $323 \mathrm{~K}$. It gives the corrosion potential $\left(\mathrm{E}_{\mathrm{corr}}\right)$, the current density $\left(\mathrm{j}_{\text {corr }}\right)$ and the polarizing resistance (PR). A compound is said to be an anodic or a cathodic inhibitor based on the corrosion potential $\left(\mathrm{E}_{\mathrm{corr}}\right)$. If the corrosion potential change is greater than $85 \mathrm{mV}$ towards anode or cathode with reference to the sample tested without inhibitor, then the inhibitor is either an anodic inhibitor or a cathodic inhibitor respectively. Otherwise, it is referred to as a mixed inhibitor [29]. As shown in table 4.1 , the difference in corrosion potential is not up to the $85 \mathrm{mV}$. This also agrees with the curves in Figs 5a-e and shows that the Artemether/Lumefantrine inhibitor acts as a mixed type inhibitor. 
International Journal of Engineering Research and Technology. ISSN 0974-3154, Volume 13, Number 6 (2020), pp. 1289-1299 (C) International Research Publication House. https://dx.doi.org/10.37624/IJERT/13.6.2020.1289-1299

Table 2: Electrochemical data of mild steel samples in $0.625 \mathrm{M}$ salt solution medium in the presence and absence of

\begin{tabular}{|c|c|c|c|c|c|}
\hline Temperature $(\mathrm{K})$ & $\begin{array}{c}\text { Inhibitor } \\
\text { concentration } \\
(\mathrm{ml})\end{array}$ & Ecorr $(\mathrm{V})$ & jeorr $\left(\mathrm{A} / \mathrm{cm}^{2}\right)$ & $\mathrm{C}_{\mathrm{r}}(\mathrm{mm} /$ year $)$ & $\operatorname{PR}(\Omega)$ \\
\hline \multirow{5}{*}{298} & 0 & -1.1834 & 0.0012 & 13.5510 & 60.6470 \\
\hline & 5 & -1.1674 & 0.0007 & 7.6314 & 43.7510 \\
\hline & 10 & -1.1542 & 0.0004 & 4.2628 & 41.2140 \\
\hline & 15 & -1.1764 & 0.0003 & 3.9598 & 95.8770 \\
\hline & 20 & -1.1626 & 0.0003 & 3.4460 & 41.2860 \\
\hline \multirow{5}{*}{308} & 0 & -1.1781 & 0.0015 & 17.2200 & 56.2590 \\
\hline & 5 & -1.1596 & 0.0010 & 12.1370 & 51.5700 \\
\hline & 10 & -1.1707 & 0.0009 & 10.0860 & 35.1670 \\
\hline & 15 & -1.1536 & 0.0008 & 8.7624 & 60.2200 \\
\hline & 20 & -0.7142 & 0.0006 & 7.0483 & 6.0182 \\
\hline \multirow{5}{*}{313} & 0 & -1.1671 & 0.0017 & 19.4770 & 45.1730 \\
\hline & 5 & -1.1121 & 0.0014 & 16.0720 & 39.6350 \\
\hline & 10 & -0.6052 & 0.0013 & 15.0760 & 5.9739 \\
\hline & 15 & -1.1521 & 0.0012 & 14.0170 & 44.8390 \\
\hline & 20 & -1.1812 & 0.0011 & 12.9130 & 57.8180 \\
\hline \multirow{5}{*}{318} & 0 & -1.1774 & 0.0019 & 22.0010 & 19.0810 \\
\hline & 5 & -0.6897 & 0.0017 & 19.5090 & 4.9063 \\
\hline & 10 & -1.1527 & 0.0015 & 17.6010 & 38.5620 \\
\hline & 15 & -1.1520 & 0.0014 & 16.0470 & 47.7890 \\
\hline & 20 & -1.2467 & 0.0013 & 15.4190 & 49.4730 \\
\hline \multirow{5}{*}{323} & 0 & -1.1526 & 0.0023 & 26.9610 & 40.2070 \\
\hline & 5 & -0.6832 & 0.0021 & 24.3280 & 5.3218 \\
\hline & 10 & -1.2094 & 0.0020 & 23.0090 & 39.9460 \\
\hline & 15 & -1.1405 & 0.0019 & 21.9500 & 60.1510 \\
\hline & 20 & -1.5592 & 0.0019 & 21.5480 & 113.1700 \\
\hline
\end{tabular}



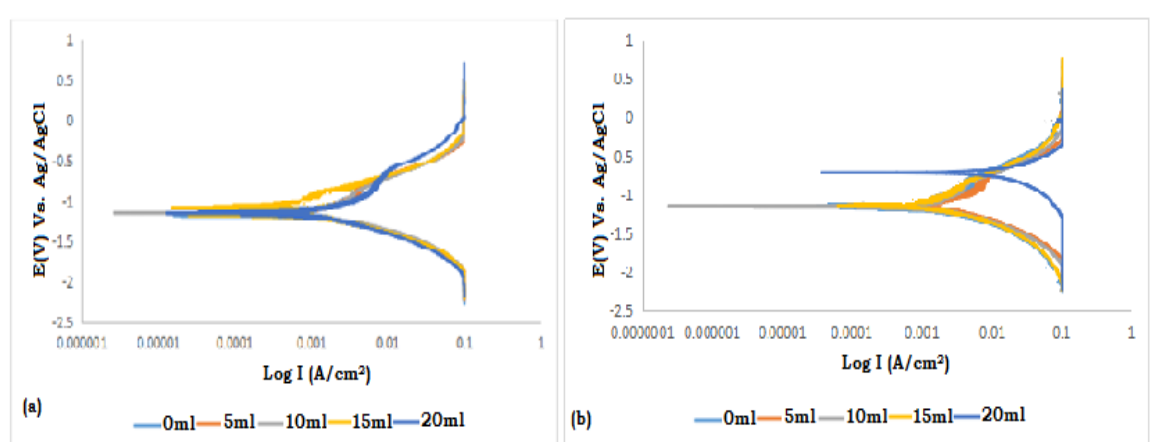

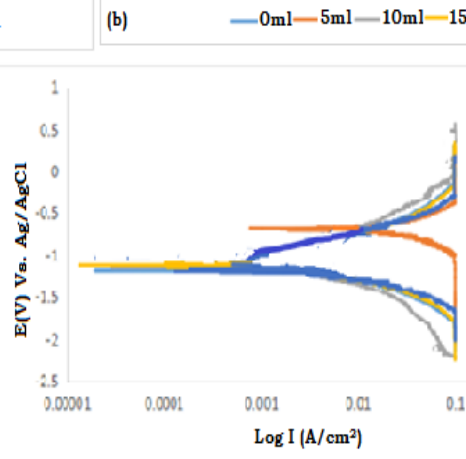

(d)
$-0 \mathrm{ml}-5 \mathrm{ml}-10 \mathrm{ml}-15 \mathrm{ml}-20 \mathrm{ml}$

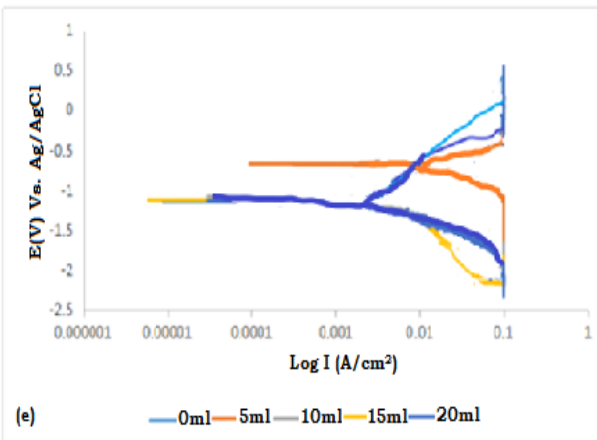

(e)

Figure 5: Polarisation curves for mild steel samples in varying amounts of inhibitor at [a] 298K [b] 308K [c] 313K [d] 318K [e] $323 \mathrm{~K}$

Adsorption isotherms are plots used to study adsorption behaviour of samples. The amounts of adsorbate based on pressure for gaseous samples and concentration for liquids at constant temperatures are presented in Figs 6-10. Five different adsorption isotherms were tested in this study, the Langmuir, Freundlich, Temkin, El-Awady and Flory-Huggins isotherms shown in Figs 6-10 respectively. Table 3 compares the fits of the isotherms based on their correlation coefficients to obtain the best fit. It is shown that the Langmuir adsorption isotherm provides the best fit. Table 4 gives the data obtained from the Langmuir isotherm. The Gibbs free energy values are greater (more positive) than $-20 \mathrm{~kJ} / \mathrm{mol}$. This suggests that a physical adsorption was carried out as chemical adsorption falls in a range of $-40 \mathrm{~kJ} / \mathrm{mol}$ or higher as attested by [29]. It is seen that the adsorptive capacities of adsorbates balance up the adsorption and desorption rates which account for effective surface coverage.

From all indication, the adsorbent surface consists of a fixed number of active sites based on its surface area and only one molecule was adsorbed at each of these active sites. It is worth mentioning that there is no interaction between the molecules adsorbed on the active sites. As such, the heat of adsorption does not change regardless of the surface coverage. The molecules that have been adsorbed remain at their adsorption sites until desorption takes place.

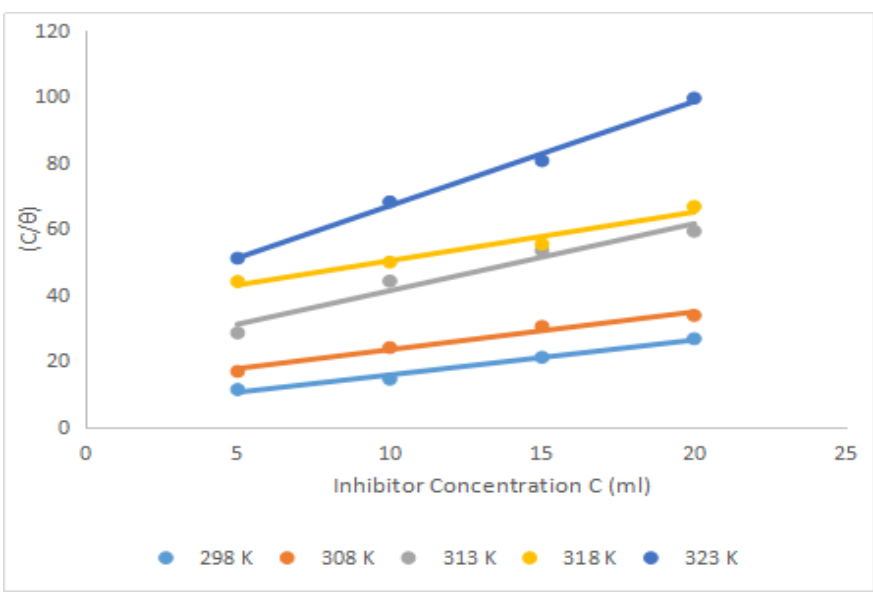

Figure 6: Adsorption plot using Langmuir isotherm

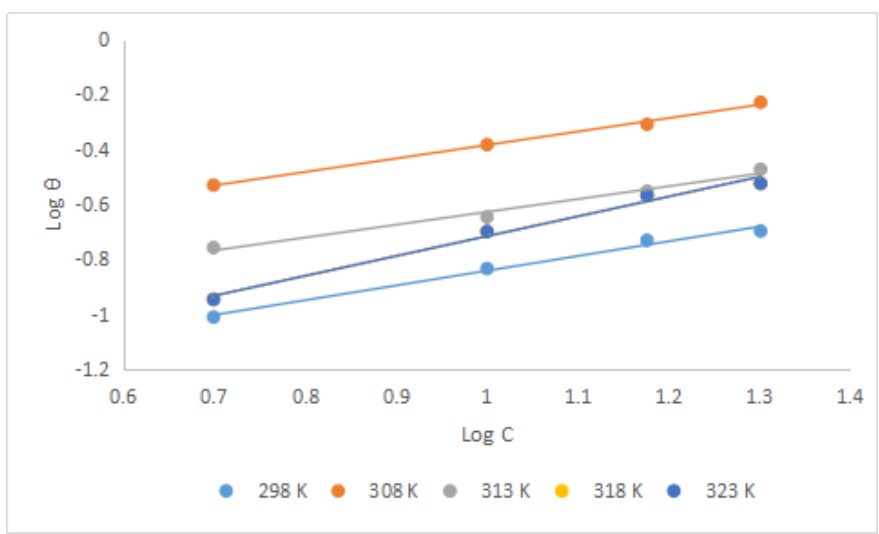

Figure 7: Adsorption plot using Freundlich Isotherm 


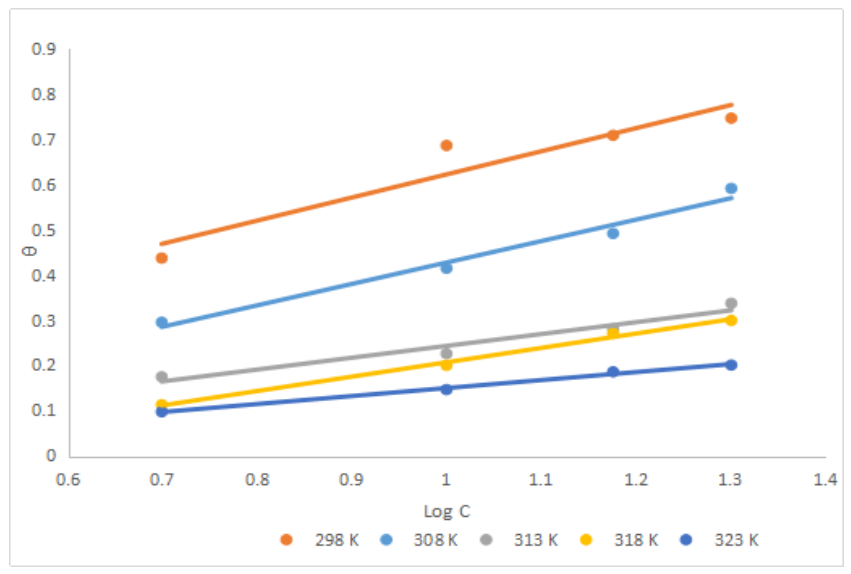

Figure 8: Adsorption plot using Temkin Isotherm

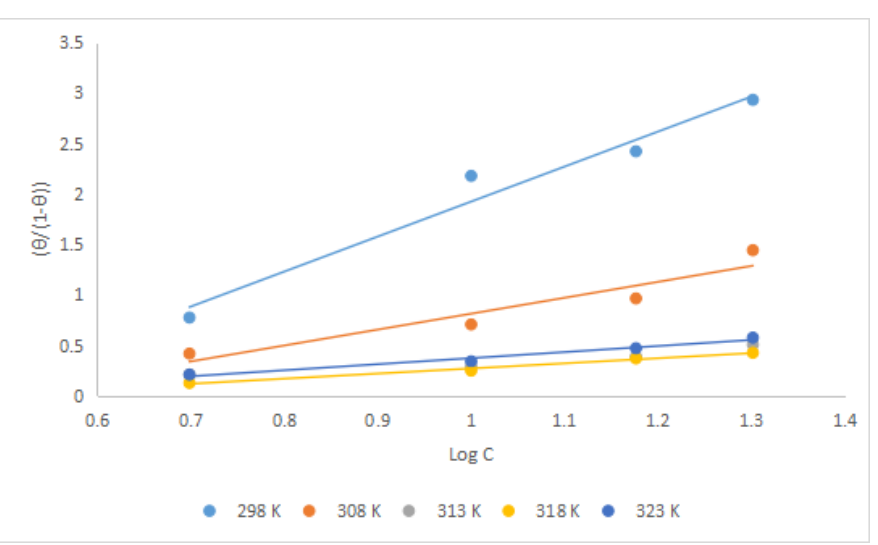

Figure 9: Adsorption plot using El-Awady isotherm

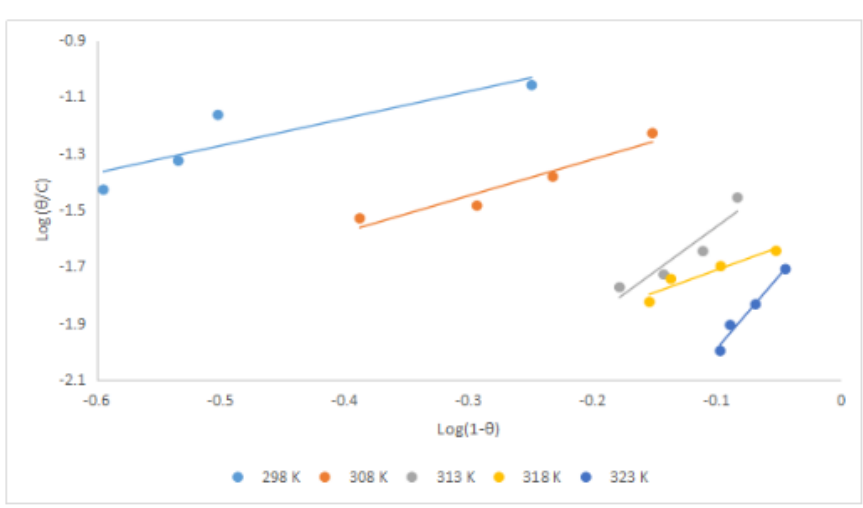

Figure 10: Adsorption plot using Flory-Huggins isotherm

Table 3: Correlation coefficients for various adsorption isotherms

\begin{tabular}{|c|c|c|c|c|c|}
\hline $\begin{array}{c}\text { Temperature } \\
(\mathbf{K})\end{array}$ & $\begin{array}{c}\text { Langmu } \\
\text { ir }\end{array}$ & $\begin{array}{c}\text { Freundli } \\
\text { ch }\end{array}$ & $\begin{array}{c}\text { Temki } \\
\mathbf{n}\end{array}$ & $\begin{array}{c}\text { El- } \\
\text { Awady }\end{array}$ & $\begin{array}{c}\text { Flory- } \\
\text { Huggins }\end{array}$ \\
\hline 298 & 0.9822 & 0.8780 & 0.8996 & 0.9649 & 0.7838 \\
\hline 308 & 0.9759 & 0.9962 & 0.9766 & 0.8985 & 0.9190 \\
\hline 313 & 0.9784 & 0.9842 & 0.9514 & 0.9207 & 0.8733 \\
\hline 318 & 0.9995 & 0.9857 & 0.9940 & 0.9877 & 0.9087 \\
\hline 323 & 0.9922 & 0.9887 & 0.9936 & 0.9750 & 0.9087 \\
\hline
\end{tabular}

Based on the Langmuir equation, a plot of concentration divided by surface coverage $(\mathrm{C} / \theta)$ against the concentration was constructed as shown in figure 4.14. This then matches equation shown below:

$$
\frac{C}{\theta}=\frac{1}{K_{a d s}}+C
$$

From the equation, the intercept gives the inverse of the adsorption coefficient $\left(\mathrm{K}_{\mathrm{ads}}\right)$ and thus, the inverse of the intercept for each temperature gives the adsorption coefficient at that temperature. To obtain the change in standard free energy of adsorption ( $\left.\Delta \mathbf{G}_{\mathbf{a d s}}\right)$, the relationship below was used:

$$
\Delta \mathbf{G}_{a d s}=-R T \ln \left(55.5 K_{a d s}\right)
$$

With $\mathrm{R}$ as the gas constant and $\mathrm{T}$ as the temperature. Since the value of the free energy of adsorption are more positive than $20 \mathrm{~kJ} / \mathrm{mol}$ as they fall within the range of -10.08 and -13.87 $\mathrm{kJ} / \mathrm{mol}$, it can be concluded that the inhibitor exhibited a physical type adsorption (physisorption) and not chemisorption. Also, since the values are negative, it shows that the adsorption was spontaneous.

Table 4: Langmuir isotherm thermodynamic data

\begin{tabular}{|l|l|l|l|}
\hline $\begin{array}{l}\text { Temperature } \\
(\mathbf{k})\end{array}$ & $\mathbf{R}^{2}$ & $\mathbf{K}_{\text {ads }}$ & $\begin{array}{l}\Delta \mathbf{G}_{\text {ads }} \\
\left(\mathbf{K J m o l}^{-1}\right)\end{array}$ \\
\hline 298 & 0.9822 & 1.0545 & -10.0843 \\
\hline 308 & 0.9759 & 1.1432 & -10.6295 \\
\hline 313 & 0.9784 & 2.0297 & -12.2961 \\
\hline 318 & 0.9995 & 1.4710 & -11.6412 \\
\hline 323 & 0.9922 & 3.1547 & -13.8735 \\
\hline
\end{tabular}

In Fig 11, the logarithms of corrosion rates were plotted against the inverse of the temperatures in order to obtain the activation energy and the pre-exponential factors based on the Arrhenius equation shown below:

$$
\log C_{r}=\frac{-E_{a}}{2.303 R T}+\log \lambda
$$

As such, the activation energy $\left(E_{a}\right)$ can be found from the slope of the graph and the pre-exponential factor from the exponential of the intercept. The activation energy is seen to increase with increase in inhibitor concentration. This shows that the inhibitor is active in preventing corrosion by limiting the oxidation reaction through an increase in the activation energy of the reaction. The entropy also increases with increasing inhibitor thus implying a spontaneous adsorption process. 


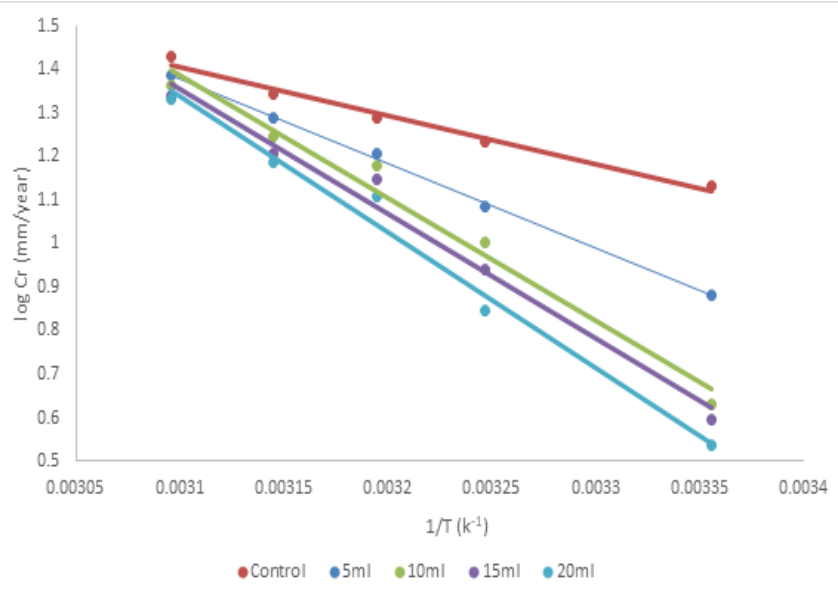

Figure 11: Arrhenius Plot for Mild Steel in $0.625 \mathrm{M} \mathrm{NaCl}$ with various concentrations of Artemether / Lumefantrine Inhibitor

To obtain the entropy and enthalpy of activation, a plot of the logarithm of corrosion rate divided by temperature $\left(\log \mathrm{C}_{\mathrm{r}} / \mathrm{T}\right)$ was drawn against the inverse of temperature as shown in figure 12. This was to linearize the transition equation given below:

$$
\frac{C_{r}}{T}=\frac{R}{N h} \exp \left(\frac{\Delta \mathrm{S}}{R}\right) \exp \left(-\frac{\mathrm{H}}{R T}\right)
$$

The enthalpy was obtained from the slope and the entropy was obtained from the intercept where $\mathrm{N}$ represents Avogadro's number and $\mathrm{h}$ represents Planck's constant. The enthalpy values are seen to be positive. This shows that the dissolution of mild steel in the salt solution medium is endothermic and suggests that the dissolution of mild steel in the salt solution medium is slow. Also, the enthalpy was seen to increase with increasing concentration of the Artemether/Lumefantrine inhibitor which implies slower dissolution of the mild steel in the presence of the inhibitor [9]. The entropy also increased with increasing inhibitor concentration. This proposes that the adsorption of the inhibitor leads to desorption of water molecules from the metal surfaces. Positive entropy values imply that the adsorption process is followed by entropy increase which is the driving force for inhibitor adsorption.

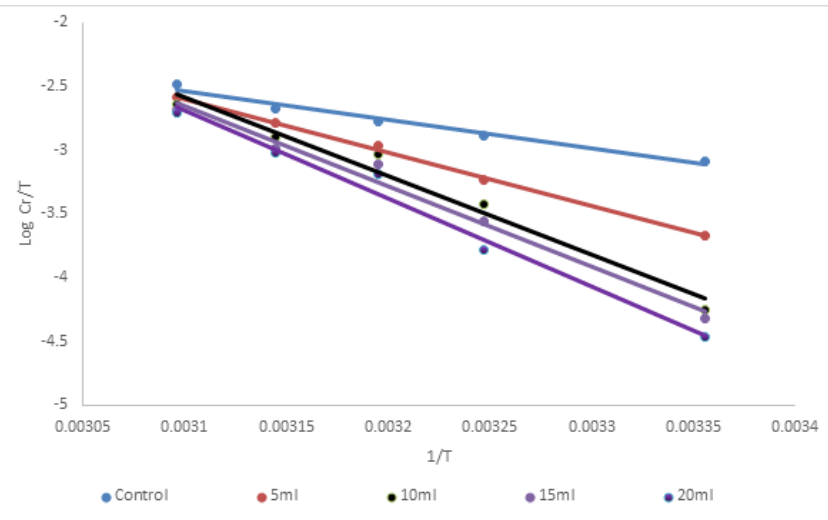

Figure12: Transition state plot for Mild Steel in $0.625 \mathrm{M} \mathrm{NaCl}$ with various concentrations of Artemether / Lumefantrine Inhibitor
Images of the surfaces of the metal samples were taken to observe the differences in corrosion effect due to presence or absence of artemether/lumefantrine inhibitor and temperature while the metals were immersed in the $0.625 \mathrm{M} \mathrm{NaCl}$ solution. Fig 13 represents scanning electron micrographs of metal samples after exposure to the corrosive environment in varying inhibitor concentrations and temperature at $300 \mathrm{X}$ magnification. In Fig 13a, the sample was tested at room temperature in the absence of inhibitor. Small holes and cracks characterised that surface which suggests pitting corrosion most likely due to the effect of chloride ions within the medium. In Fig 13b-f, the sample was tested with $20 \mathrm{ml}$ of artemether/lumefantrine inhibitor applied. The corrosive effect is less pronounced with fewer pits and a slight inhibitor layer on the surface which shows that the inhibitor is effective. In Fig. 13f the sample contains heteroatom and films evolution of artemether/lumefantrine inhibitor drugs. There is a massive surface decrease in corrosion deterioration even at higher temperature. This establishes that there is a displayed on reduction in severity of pitting evolution and corrosion product.
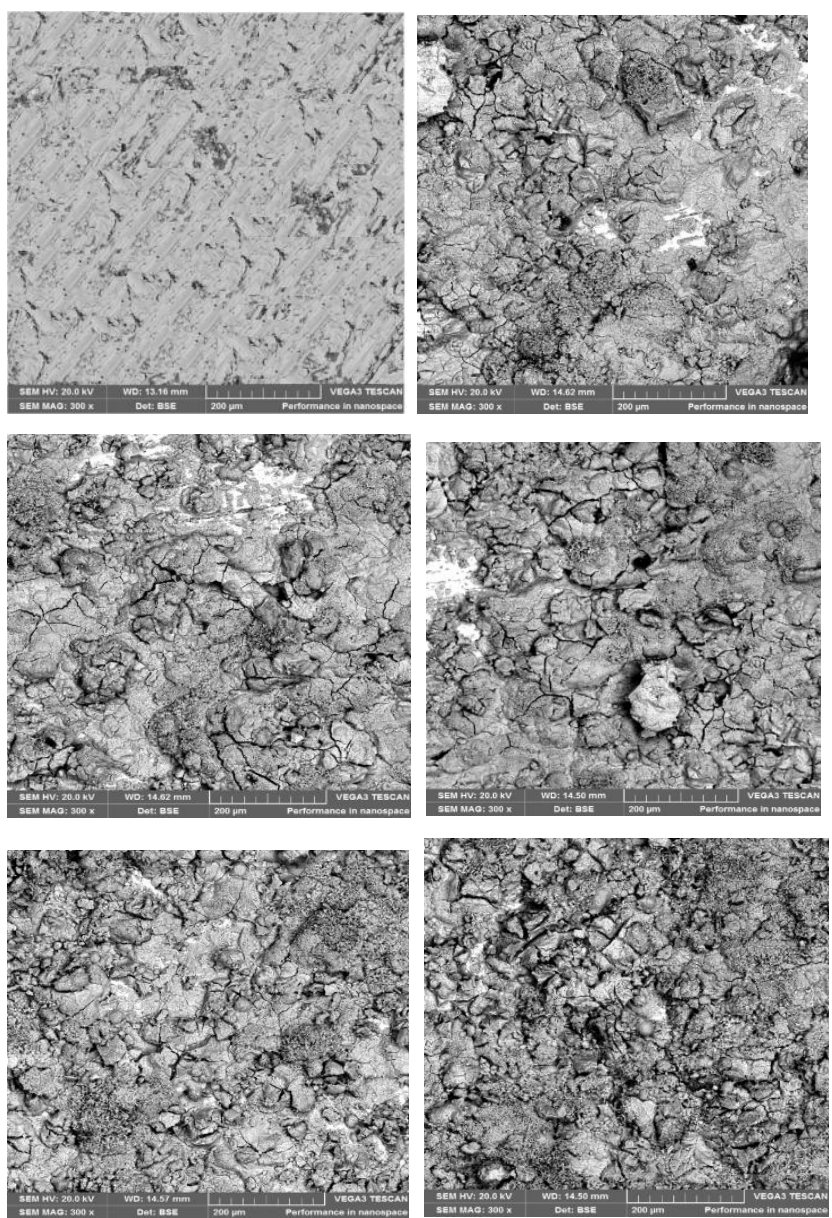

Figure 13: SEM micrograph (a) As-received mild steel (b) $20 \mathrm{ml}$ inhibitor at $298 \mathrm{~K} \mathrm{(c)} 20 \mathrm{ml}$ inhibitor at $308 \mathrm{~K}$ (d) $20 \mathrm{ml}$ inhibitor at $313 \mathrm{~K}$ (e) $20 \mathrm{ml}$ inhibitor at $313 \mathrm{~K}$ (f) $20 \mathrm{ml}$ inhibitor at $323 \mathrm{~K}$ 
International Journal of Engineering Research and Technology. ISSN 0974-3154, Volume 13, Number 6 (2020), pp. 1289-1299

(C) International Research Publication House. https://dx.doi.org/10.37624/IJERT/13.6.2020.1289-1299

Figs 14 and 15 show the Energy dispersive $x$-ray spectroscopy analysis (EDS) of inhibited and uninhibited samples in order to determine the composition of artemether/lumefantrine and macromolecular element presents. From all observation, EDS spectrum for uninhibited sample in Fig 14 sample at $323 \mathrm{~K}$ shows high percentage of iron and oxygen. For the inhibited sample in Fig 15, there is a suppression of the iron composition from $97.2 \%$ to $37.6 \%$ after exposure. More so, there is presence of surface active element such as $\mathrm{C}, \mathrm{O}, \mathrm{Si}$, $\mathrm{Na}, \mathrm{Cl}, \mathrm{Al}$ and $\mathrm{S}$ passivating active site. No doubt, there is less chloride ion, initiation and penetration metal interface with the help of molecular compounds of artemether/lumefantrine active agent.

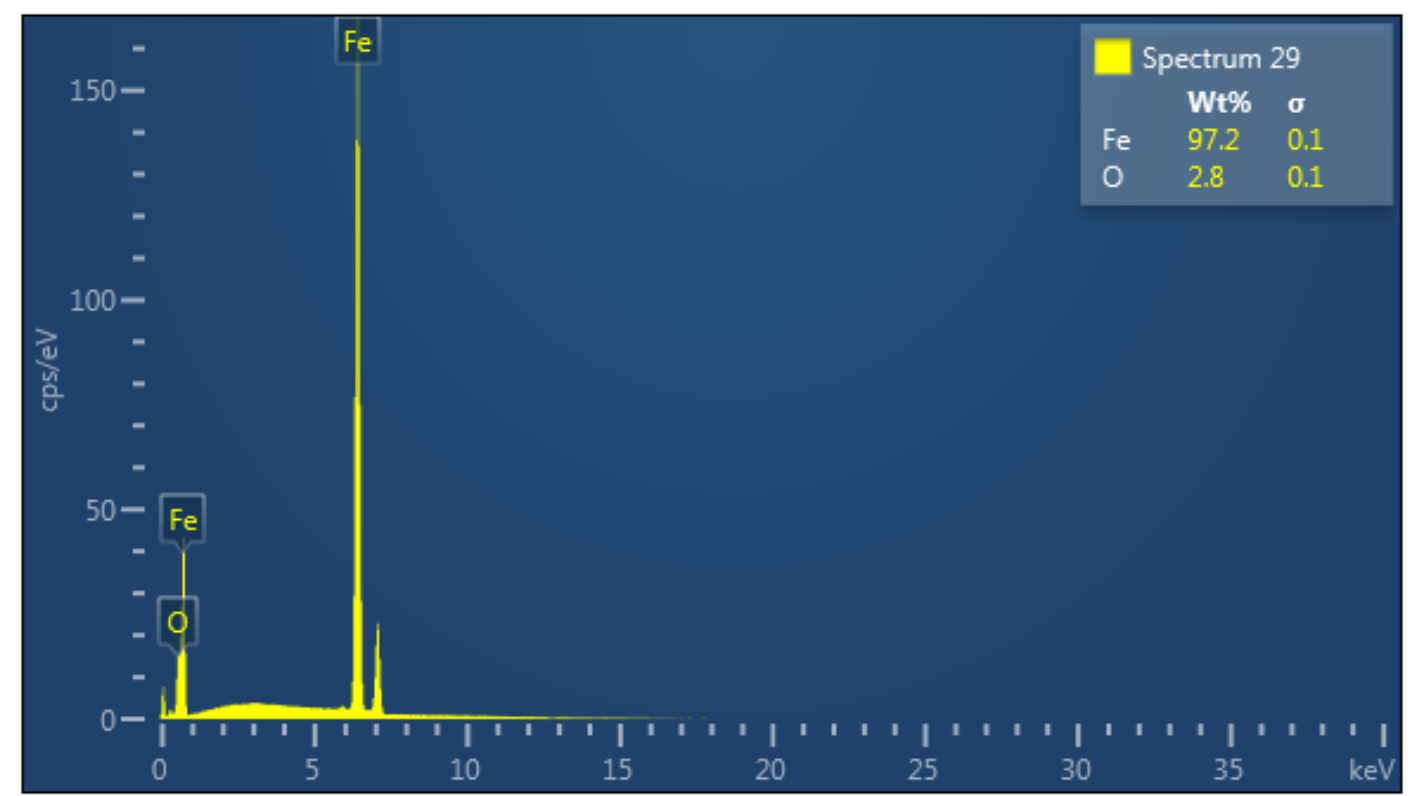

Figure 14: EDS spectrum mild steel without inhibitor at $323 \mathrm{~K}$

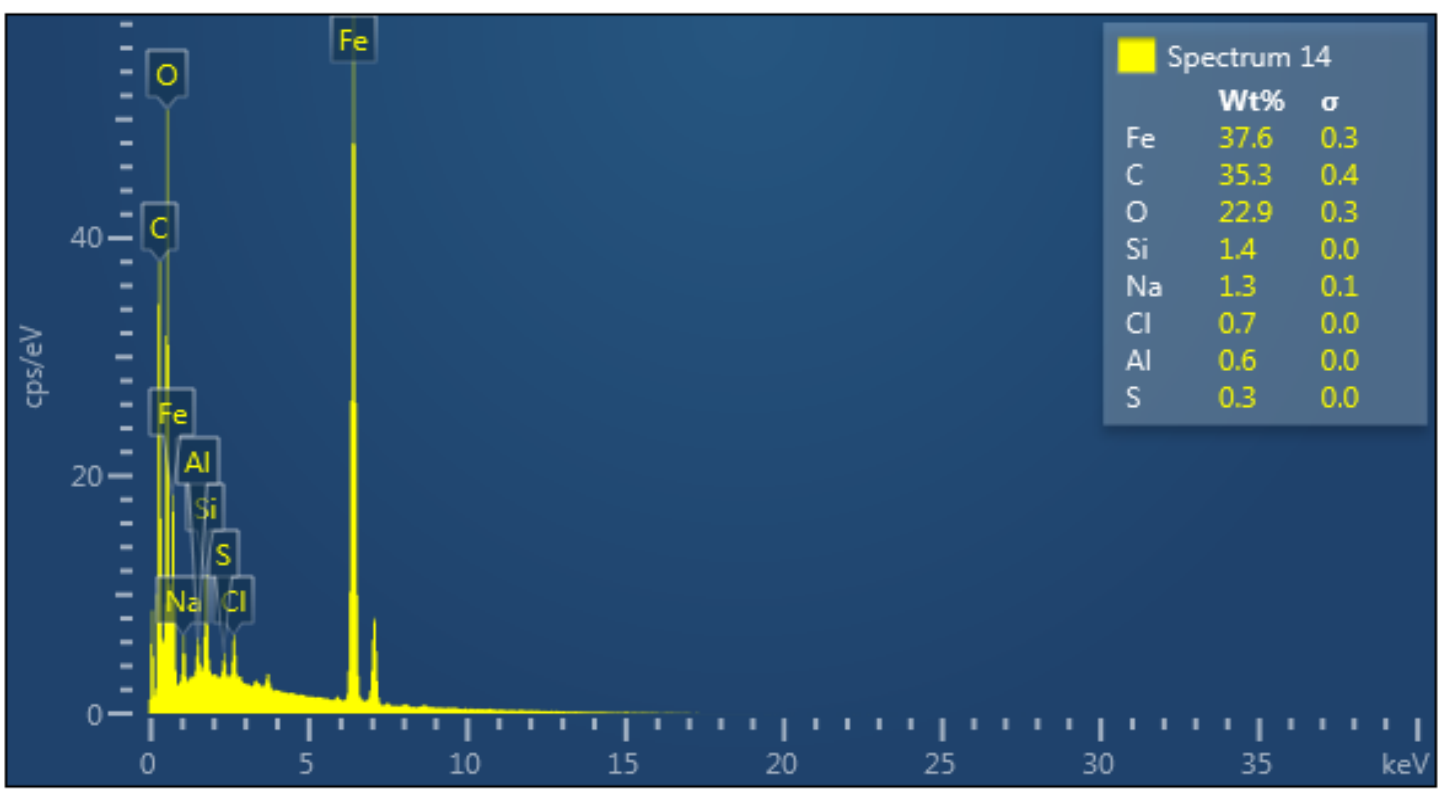

Figure 15: EDS spectrum of 20ml artemether/lumefantrine inhibited mild steel at $323 \mathrm{~K}$

\section{CONCLUSION}

The study of inhibitive performance and mechanism of Artemether/Lumefantrine was studied. Artemether/Lumefantrine inhibits the corrosion of mild steel in $0.625 \mathrm{M}$ salt solution perfectly with an inhibition efficiency of up to $75 \%$ at $298 \mathrm{~K}$ with $20 \mathrm{ml}$ of the inhibitor. The polarisation curves showed that the inhibitor operates with a mixed inhibition method since both the cathodic and anodic reactions were affected by the addition of artemether/lumefantrine inhibitor. The Langmuir adsorption isotherm best matches the behaviour of the inhibitor in the 
experiment with a minimum correlation coefficient of 0.975 . The inhibition efficiency reduced with increase in temperature but increased with increase in inhibitor concentration which suggests that the inhibition efficiency is inversely proportional to temperature but directly proportional to concentration. The entropy values for the reaction were positive in the presence of inhibitor and increased with increase in inhibitor concentration which shows the driving force for adsorption of inhibitor onto the surface of the metal which leads to desorption of water molecules from the surfaces. The scanning electron micrograph showed noticeably lower amount of pitting on the surface of the metals with increased inhibitor concentration and greater pitting at higher temperatures.

\section{ACKNOWLEDGEMENT}

The authors would like to acknowledge Surface Laboratory headed by Dr. Ojo Sunday Isaac Fayomi and Covenant University Centre for Research Innovation and Discovery (CUCRID) Ota, Nigeria for financial support.

\section{REFERENCES}

[1] Ansari, K. R., Quraishi, M. A., \& Ebenso, E. (2013). Electrochemical and thermodynamic investigation of diclofenac sodium drug as a potential corrosion inhibitor for mild steel in hydrochloric acid. International Journal of Electrochemical Science, 12860-12973.

[2] ASTM International. (2002). Standard Terminology Relating to Corrosion and Corrosion Testing. West Conshohocken.

[3] Ayawei, N., Ebelegi, A. N., \& Wankasi, D. (2017). Modelling and Interpretation of Adsorption Isotherms. Journal of Chemistry.

[4] Ayawei, N., Ekubo, A. T., \& Wankasi, D. (2015). Adsorption of congo red by Ni/Al-CO3: equilibrium, thermodynamic and kinetic studies. Oriental Journal of Chemistry, 1307-1318.

[5] Dubova, V., \& Kris, J. (2004). Corrosion tests of a steel pipeline water distribution system. SLOVAK Journal of civil Engineering, 18-22.

[6] Eddy, N. O., \& Ebenso, E. E. (2010). Adsorption and quantum chemical studies on Cloxacillin and halides for the corrosion of mild steel in acidic medium. International Journal of Electrochemical Science, 731750.

[7] Eddy, N. O., \& Odoemelam, S. A. (2008). Norfloxacin and Sparfloxacin as corrosion inhibitors for zinc. Effect of concentrations and temperature. Journal of Materials Science, 87-96.

[8] Faritov, A. T., Rozhdestvenskii, Y. G., Yamshchikova, S. A., Minnikhanova, E. R., \& Tyusenkov, A. S.
(2016). Improvement of the linear polarization resistance method for testing steel corrosion inhibitors. Russian Metallurgy, 1036-1041.

[9] Ghazoui, A., Benchat, N., El-Hajjaji, F., Taleb, M., Rais, Z., Saddik, R., . . . Hammouti, B. (2017). The study of the effect of ethyl (6-methyl-3-oxopyridazin-2yl) acetate on mild steel corrosion in $1 \mathrm{M} \mathrm{HCl}$. Journal of Alloys and Compounds, 510-517.

[10] Goyal, M., Kumar, S., \& Bahadur, I. (2018). Organic corrosion inhibitors for industrial cleaning of ferrous and non-ferrous metals in acidic solutions: A review. Journal of Molecular Liquids, 565-573.

[11] Gupta, N. K. (2017). Application of expired drugs in corrosion inhibition of mild steel. Original Research Article International Journal of Pharmaceutical Chemistry and Analysis, 8-12.

[12] Ilayaraja, G., Sasieekhumar, A., \& Dhanakodi, P. (2011). Inhibition of mild steel corrosion in acidic medium by aqueous extract of Trida procumbens. EJournal of Chemistry, 685-688.

[13] Ivanković, A., Dronjić, A., Bevanda, A. M., \& Talić, S. (2017). Review of 12 Principles of Green Chemistry in Practice . International Journal of Sustainable and Green Energy, 39-48.

[14] Kong, L., Zhang, B., \& Fang, J. (2017, September 149). Study on the applicability of bactericides to prevent concrete microbial corrosion. Construction and Building Materials, pp. 1-8.

[16] Ladha, D. G., Naik, U. J., \& Shah, N. (2013). Investigation of cumin (Cuminum Cyminum) extract as an eco-friendly green corrosion inhibitor for pure Aluminium in acid medium. Journal of Materials and Environmental Science, 701-708.

[17] Mahdi, A. S. (2014). Amoxicillin as green corrosion inhibitor for concrete reinforced steel in simulated concrete pore solution containing chloride. International Journal of Advanced Research in Engineering and Technology, 99-107.

[18] Pathak, R. K., \& Mishra, P. (2013). Drugs as Corrosion Inhibitors: A Review. International Journal of Science and Research, 671-677.

[19] Shah, A., Hasan, F., Hameed, A., \& Ahmed, S. (2008). Biological degradation of plastics: A comprehensive review. Biotechnology Advances, 246-265.

[20] Sheir, L., \& Jarman, R. (n.d.). Design for Prevention of Corrosion in Buildings and Structures, CorrosionVolume 2, Corrosion Control - third edition

[21] Sheldon, R. (2018). Metrics of Green Chemistry and Sustainability: Past, Present, and Future. ACS Sustain. Chem. Eng, 32-48.

[22] Stern, M. (1958). The Mechanism of Passivating type Inhibitors. J. Electrochem. Soc., 638-647.

[23] Vermeirssen, E., Dietschweiler, C., Werner, I., \& 
International Journal of Engineering Research and Technology. ISSN 0974-3154, Volume 13, Number 6 (2020), pp. 1289-1299

(C) International Research Publication House. https://dx.doi.org/10.37624/IJERT/13.6.2020.1289-1299

Burkhardt, M. (2017). Corrosion protection products as a source of bisphenol A and toxicity to the aquatic environment. Water Res, 586-593.

[24] Xu, D., Li, Y., Gu, \& T. (2016). Mechanistic modeling of biocorrosion caused by biofilms of sulfate reducing bacteria and acid producing bacteria. Bioelectrochemistry, 52-58.

[25] Abioye, O.P, Loto, C. A. and Fayomi. O. S. I. (2019) "Evaluation of anti-biofouling progresses in marine application." Journal of Bio-and Tribo-Corrosion 5.1 22.

[26] Akande, I. G., Oluwole, O. O. and Fayomi. O. S. I. (2019)"Optimizing the defensive characteristics of mild steel via the electrodeposition of $\mathrm{ZnSi3N} 4$ reinforcing particles." Defence Technology 15.4 526-532.

[27] Monyai, T., Fayomi, O. S. I. and Agboola. O. Popoola API (2019) "Integration of MoO 2 Composite on the Micro-evolution and Anticorrosion Mitigation of $\mathrm{Zn}-$ Ni-MoO 2 Thin Films Coating by Electrodeposition System." Journal of Bio-and Tribo-Corrosion 5.1 17.

[28] World Health Organization. (2019). World Health Organization Model List of Essential Medicines. World Health Organization.

[29] Xu, X., Singh, A., Sun, Z., Ansari, K. R., \& Lin, Y. (2017). Theoretical, thermodynamic and electrochemical analysis of biotin drug as an impending corrosion inhibitor for mild steel in $15 \%$ hydrochloric acid. Royal Society Open Science 